\title{
ACTIVIDADES DE LOS DEPARTAMENTOS DE FILOLOGÍA HISPÁNICA Y PORTUGUESA DEL INSTITUTO DE ESTUDIOS ROMÁNICOS (IER) DE LA UNIVERSIDAD CAROLINA DE PRAGA, 2010-2015
}

En el transcurso del último quinquenio, los miembros de los Departamentos de Filología Hispánica y Portuguesa realizaron, además de su habitual trabajo docente, numerosas actividades tanto en el campo nacional como internacional que reflejan su amplio quehacer académico en la esfera literaria y lingüística.

Los resultados de su investigación se presentaron en una serie de eventos científicos internacionales que tuvieron lugar en España, Portugal, Italia, Chile, Eslovenia, Bulgaria, Polonia, entre otros. En 2010, la Dra. Vlasta Dufková y la Dra, Jaroslava Jindrová del Departamento de Filología Portuguesa participaron en las II Jornadas de Língua Portuguesa e Culturas Lusófonas da Europa Central e de Leste en la Universidad Sveti Kliment Ohridski, Sofía (Bulgaria), presentando las ponencias, respectivamente, "Entre Romeu e Raskólnikov (Amor de perdição no contexto da literatura europeia)" y "Algumas observações sobre o Novo Acordo Ortográfico”. El Dr. Juan Sánchez expuso su ponencia "Intertextualidad y culturalismo en su marco hermenéutico: Octavio Paz y Pere Gimferrer" en el XVII Congreso de la Asociación Internacional de Hispanistas, en la Università della Sapienza de Roma. El mismo año, la Dra. Anna Mištinová fue invitada como conferencista plenaria al XIII Congreso Internacional de Humanidades. Palabra y Cultura en América Latina: herencias y desafíos, celebrado en conmemoración del 200 Aniversario de la independencia de Chile en la Universidad Metropolitana de Santiago de Chile. Su conferencia fue dedicada a la relación del castellano, las variedades hispanoamericanas y la identidad nacional. El congreso fue transmitido por medio de una video-conferencia a otros países de Hispanoamérica.

En 2011, en el III Simposio Percepcija časa $v$ jeziku in književnosti - La percepción del tiempo en lengua y literatura - organizado en ocasión del treinta aniversario de la fundación de la hispanística eslovena por la Universidad de Lublana - A. Mištinová presentó la ponencia sobre la expresión del tiempo en el español de América. J. Hricsina participó en 2012 y 2013 en el simposio Horizontes do Saber Filológico (Universidad Sveti Kliment Ohridski, Sofía) y en el I Congresso dos lusitanistas polacos (Universidad Jagellónica, Cracovia). En sus contribuciones "O verbo auxiliar tenere nas línguas românicas" y "Substituição do gerúndio pela construção a + infinitivo no Português Europeu (estudo diacrónico)" se concentró en los problemas del sistema verbal.

A base de la invitación de la Presidencia de la Federación Internacional de Asociaciones de Profesores de Español FIAPE, A. Mištinová impartió una conferencia plenaria "Variedades del español: su unidad y diferenciación" en el V Congreso Internacional de la FIAPE ¿Qué español enseñar y cómo? Variedades del español y su enseñanza que tuvo lugar en Cuenca en junio de 2014. En aquella ocasión, la hispanista checa y el Dr. Walther I. Bernecker (Alemania) fueron nombrados como Socios de Honor "por sus roles relevantes tanto en la constitución de la FIAPE como en su desarrollo académico y político, presidiendo durante años las respectivas asociaciones nacionales y contribuyendo en forma permanente al cumplimiento de los objetivos de FIAPE y a la consolidación del español".

Dentro del marco del programa Erasmus se realizaron numerosos intercambios de estudiantes. Algunos colegas del IER dictaron conferencias en las universidades homólogas de España y Portugal: J. Jindrová impartió en la Universidad Sveti Kliment Ohridski (Sofía, 2010) dos conferencias "Reflexos do 25 de Abril na vida das nova gerações" y "Problemas na criação dos dicionários bilingues". P. Čermák presentó en la Universidad de Santiago de Compostela (2010) los temas de la historia más antigua del Círculo Lingüístico de Praga, a la luz de las fuentes documentales. J. 
Hricsina dictó con la conferencia "A comparãçao dos sistemas verbais em Portugus e em Checo" (Faculdad de Letras de la Universidad de Lisboa, 2011).

A. Mištinová realizó en la Universidad Michoacana de San Nicolás de Hidalgo (Morelia, México, 2012) un proyecto de investigación, dedicado a los aspectos diacrónicos y sincrónicos de la variación del español de México desde el punto de vista de la geografía lingüística y contacto del castellano y lenguas indígenas, especialmente el purépecha.

En la República Checa, en 2010, la Prof. Anna Housková participó en dos eventos praguenses con las ponencias "Juan Ruiz de Alarcón, un mexicano en el teatro del Siglo de Oro" (Simposio Culturas Iberoamericanas - Transteatral, Divadelní ústav - Instituto de Teatro, Praha) y "La traducción de ensayos hispánicos" (Encuentro checo-español. Posibilidades y límites de la comunicación intercultural, Instituto de Translatología de la Universidad Carolina). En el campo de filología portuguesa, los miembros del IER organizaron en la Facultad de Filosofía y Letras el I coloquio de la Sociedad de portugalistas checos La portugalística checa - cuestiones y perspectivas (2012), en el que fueron presentados los diferentes temas, relacionados con la lingüística y literatura, así como IV Jornadas de língua portuguesa e culturas lusófonas da Europa central e de Leste (2014). J. Hriscina participó además en el III coloquio de la Sociedad de portugalistas en la Universidad Masaryk de Brno (2014), exponiendo el tema de las tendencias evolutivas del subsistema consonántico en portuqués.

Los hispanistas del IER tomaron parte en los simposios de las universidades checas de Olomouc, Brno, Liberec y České Budějovice. En los Encuentros de romanistas de la Universidad Palacký de Olomouc, que se realiza cada dos años, el nuevo director del IER, Prof. P. Čermák, habló sobre los proyectos lingüísticos en los que participaban los investigadores del IER (Jazyk jako produkt lidské činnosti - Lengua como producto de la actividad humana; Český národní korpus a korpusy dalších jazyki̊ - Corpus Nacional Checo y los corpus de otros idiomas; Románské jazyky ve světle jazykových korpusů - Lenguas romances a la luz de los corpus lingüísticos). En el Encuentro de hispanistas, organizado por la Universidad Masaryk de Brno (2012), participaron A. Mištinová y D. Poláková con sus contribuciones sobre los resultados de investigación en México y el cuento hispanoamericano, respectivamente. Las dos, junto con P. Čermák, presentaron sus ponencias también en el coloquio Pasión por el hispanismo de la Universidad de Liberec (2013) que fueron publicadas posteriormente en la Actas del simposio, igual que las del Encuentro de hispanistas "Al pie de la (s) letra $(s)$ ", efectuado en la Universidad de la Bohemia del Sur (2014).

En cuanto a las publicaciones editadas en la República Checa, entre las obras más relevantes de la seccion de literatura figuran la monografía Visión de Hispanoamérica. Paisaje, utopía, quijotismo en el ensayo y en la novela, por Anna Housková, directora del IER de muchos años (Praha: Karolinum, 2010), La tesitura de La Celestina, por Juan Sánchez (Praha: Karolinum, 2012) y João Guimarães Rosa: Dál - dál a dál (Praha: Torst, Biblioteca lusobrasileña, 2010); traducción comentada de Dão-lalalão y de entrevista de autor con Günter Lorenzo, por Vlasta Dufková. En el libro coordinado por Daniel Nemrava Disturbios en la Tierra sin Mal: Violencia, política y ficción en América Latina (Buenos Aires: Ejercitar la Memoria Editores, 2013), que reúne textos de escritores hispanoamericanos y críticos de varios países, A. Housková aportó el artículo "Antinomía y armonía en el modernismo". La sección de lingüística contribuyó con los volúmenes de Mluvnice současné španělštiny. (Gramática del español contemporáneo), la Sintaxis del español actual, por. Bohumil Zavadil y su alumno Petr Čermák (Praha: Karolinum, 2010) y la Gramática aplicada de la lengua española, por P. Čermák y D. Andrés Castillo (Praha: Karolinum, 2011). El mismo año, A. Housková publicó las "Traducciones checas de ensayos hispánicos" en el libro Posibilidades y límites de la comunicación intercultural (Ed. J. Králová, Ibero-Americana Pragensia, Supplementum 27, Praha: Karolinum, 2011), así como el estudio "Rozdílnost kultur v iberoamerické filosofii a kultuře" (Diversidad de culturas en la filosofía y la cultura de Iberoamérica) en Moderní svět v zrcadle literatury a filosofie (El mundo moderno en el espejo de literatura y filosofía (Ed. M. Petř́iček. Praha: Hermann a synové).

En 2013 fue editado el nuevo volumen de Romanistica Pragensia XIX. Les langues romanes à la lumière des corpus linguistiques (Acta Universitatis Carolinae - Philologica 2, red. P. Čermák), en el que aparecieron los artículos de P. Čermák (Las posibilidades de estudio ofrecidas por los 
corpus paralelos: el caso del prefijo español re-), Z. Krinková (La incorporación de los préstamos españoles en el caló: la rivalidad entre sufijos a la luz del corpus), D. Kratochvílová (Selección de modo indicativo o subjuntivo con adverbios como quizá(s), tal vez, posiblemente y probablemente), J. Hriscina (A posição do adjetivo no sintagma nominal no Português contemporâneo: análise corporal) y otros.

Los trabajos de investigadores del IER se publicaron también en el extranjero, p. ej., en Francia, Italia, Alemania, Argentina, Chile, Eslovaquia, Eslovenia, Bulgaria y España. Figuran entre ellos dos estudios editados en Francia e Italia, por A. Mištinová: "La evolución de principios metodológicos en Comenius: de la Janua Linguarum Reserata a Orbis Pictus" (Recherches. Culture et Histoire dans l'Espace Roman. 05. Enseigner les

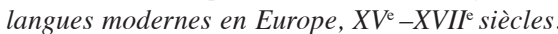
Marie-Hélène Maux-Piovano (dir.), Strasbourg: Université de Strasbourg, 2010) y «La proyección checa de métodos y manuales plurilingües en los siglos XVI y XVII: de Valerius a Comenius (Ed. J. Villoria, Dai maestri di lingue ai professori di lingue in Europa. Quaderni de CIRCIL. Quaderni de ricerca. Bologna/Granada: Centro interuniversitario di Ricerca sulla Storia degli Insegnamenti Linguistici. Alma-DL, CIRSIL, SEHEL y SIHFLES, 2010). En este contexto cabe mencionar que en 2012 a Anna Mištinová le fue otorgada la Medalla "Comenius" por la investigación en la esfera de comeniología y pedagogía, ante todo en el campo de la enseñanza de idiomas, así como por la divulgación de la obra de Comenius en el extranjero, en una serie de congresos, conferencias y publicaciones.

En Alemania, en el volumen El escritor y el intelectual entre dos mundos (Eds. C. Chantraine-Braillon, N. Giraldi Dei Cas, F. Idmhand. Madrid/Frankfurt am Main: Iberoamericana/Vervuert, 2010) se publicó el estudio de A. Housková "La utopía de América y el quijotismo". La misma autora escribió el artículo "Garantía personal en los ensayos de Ernesto Sabato" (Buenos Aires: Centro de Estudios Poéticos Alétheia, 2011), en ocasión del centenario del nacimiento del escritor argentino. En Eslovaquia fue editado el trabajo de J. Sánchez "Calisto, el desconocido de sí mismo" (Philologica XXI, Supplementum I, Bratislava, 2012). En Bulgaria se publicó la ponencia de J. Hricsina "O verbo auxiliar tenere nas línguas românicas" (Y. Andreeva (coord.). Horizontes do Saber Filológico. Sofía: Editorial Universitaria Sveti Kliment Ohridski, 2014). En el extranjero fueron editados también tres estudios escritos por A. Mištinová: en Chile, "El castellano, variedades hispanoamericanas y la identidad nacional (mirada desde la República Checa)" en Contextos. Estudios de Humanidades y Ciencias Sociales. (Santiago de Chile: Universidad Metropolitana de Ciencias de Educación, 2011); en Eslovenia, "La expresión del tiempo en las variedades hispanoamericanas del español" (Verba Hispanica, XX/1, ed. B. Kalenič Ramšak, Lublana, 2012); en España, "Variedades del español: su unidad y diferenciación" (Ministerio de Educación, Cultura y Deporte, FIAPE. Madrid: RedEle 2014/15); en la República Checa, en las Actas del simposio de hispanistas checos que tuvo lugar en Brno (Eds. A. Alchazidu, P. Stehlík, Encuentro de hispanistas, 2012. Brno: Masarykova univerzita, 2013) aparecieron las contribuciones de A. Mištinová (Cuestiones actuales de la investigación del español de México) y de D. Poláková (El gran género pequeño. Reflexiones sobre el cuento hispanoamericano); en las Actas de Liberec (Eds. M. Valeš, S. Míča, Diversidad lingüística del español, Liberec: Universidad Técnica de Liberec, 2013), las de P. Čermák (Norma lingüística: la tradición española frente a la tradición checa) y de A. Mištinová (Diversidad y diferenciación del español: ¿La norma policéntrica contra la unidad?). En el volumen Héroe y antihéroe en la literaturas hispánicas (Eds. J. Demlová, S. Míča, Liberec: Universidad Técnica de Liberec, 2013), se publicó la ponencia de D. Poláková "José Bastida, el héroe cervantino de Gonzalo Torrente Ballester”. En las Actas del simposio Al pie de la(s) letra(s). Encuentro de hispanistas (České Budějovice: Universidad de la Bohemia del Sur, 2014) se incluyeron los textos de P. Čermák "Lenguas románicas y el checo a la luz de los corpus paralelos" y de D. Poláková "El hechizo de Salomé en el fin de siècle".

En lo que se refiere a otras publicaciones cabe mencionar los artículos de P. Čermák, J. Hriscina y D. Poláková, respectivamente: "Cien años de la Revista de Filología Moderna" (Časopis pro moderní filologii, 93, No. 1, 2011); "Evolução do sistema vocálico do Latim clássico ao Português moderno (tentativa da verificação in corpora)" (Études romanes de Brno, 34/2013) y "Las fuerzas fantásticas argentinas. El cuento fantástico modernista" (Ed. J. Opatrný, Las relaciones checo-argentinas, Ibero-Americana Pragensia Supplementum 37, Praha: Karolinum, 2014). 
El mismo año, a la Dra. Anna Mištinová, quien dirigió más de diez años el Departamento de Filología Hispánica del IER y presidió la Asociación de Profesores de Español en la República Checa, le fue otorgada por Su Majestad Juan Carlos 1, Rey de España, la Encomienda de la Orden del Mérito Civil "por su labor docente, académica, investigadora y de divulgación, por su permanente y especial colaboración, y como un homenaje a quien ha contribuido de forma sustancial, y en numerosas iniciativas, al apoyo del mejor conocimiento del español y a la difusión de la lengua española". La alta condecoración la recibió de las manos del Excmo. Sr. Pascual Ignacio Navarro Ríos, Embajador de España, en un acto solemne, celebrado el 4 de abril de 2014 en Praga.

La actividad más importante del IER fue el Encuentro de hispanistas "Las palabras (des) atadas", organizado junto con el Instituto de Translatología 16 y 17 de octubre de 2015. El simposio representó una continuación digna de la tradición de encuentros anteriores de hispanistas checos. En la inauguración intervinieron con sus discursos el Excmo. Sr. Pedro Calvo-Sotelo, Embajador de España; Ramiro Villapadierna, director del Instituto Cervantes; Miriam Friedová, Decana de la Facultad de Filosofía y Letras; Petr Čermák, director del IER, y Jana Králová, vicedirectora del Instituto de Translatología. Participaron en él decenas de hispanistas checos, eslovacos, polacos y españoles, presentando en varias secciones una serie de interesantes temas literarios y lingüísticos.

por Anna Mištinová (Praga) (Escrito en español por la autora) 